\title{
Monitoria acadêmica e formação profissional em saúde: uma revisão integrativa
}

\author{
Academic monitorship and professional training in health: \\ an integrative review
}

Laís Vargas Botelho¹, Ana Eliza Port Lourenço², Maria Gouvêa de Lacerda1', Larissa Escarce Bento Wollz²

${ }^{1}$ Curso de Nutrição, Universidade Federal do Rio de Janeiro (UFRJ) - Macaé (RJ), Brasil.

${ }^{2}$ Núcleo de Estudos Plurais em Educação, Alimentação e Humanidades, UFRJ - Macaé (RJ), Brasil.

DOI: https://dx.doi.org/10.7322/abcshs.v44i1.1140

\section{RESUMO}

A monitoria é uma estratégia que pode auxiliar na formação profissional em saúde, ao proporcionar um canal dialógico entre docentes e discentes e favorecer os processos de ensinoaprendizagem. Sendo assim, o objetivo deste estudo foi revisar a literatura sobre monitoria e formação profissional em saúde no Brasil, identificando suas potencialidades e dificuldades. Tratase de uma revisão integrativa com busca sistemática de artigos publicados até abril de 2017 nas bibliotecas SciELO e Biblioteca Virtual em Saúde. Foram recuperados 13 artigos, a maioria sobre monitoria em instituições públicas do Sul e Sudeste, sendo sete somente sobre Enfermagem ou Medicina. Identificou-se como potencialidades da monitoria: estreitamento de relações entre alunos, ampliação do aprendizado e da autonomia discente e aproximação do monitor à docência. As dificuldades foram: escassez de tempo para trabalho em equipe e baixa adesão dos alunos às atividades. Observou-se que a maioria dos estudos possui cunho descritivo e não enfatiza os aspectos teóricopedagógicos relacionados. Ainda assim, o conjunto dos artigos sugere que a monitoria tem potencial de agregar ao aprendizado autonomia, criticidade e humanização, em consonância com os princípios do Sistema Único de Saúde. Conclui-se que o tema da monitoria encontra-se permeável para novos estudos e reflexões acerca do processo de ensino e aprendizagem voltado às especificidades das diferentes profissões da área de saúde. Seria pertinente discutir nas diversas instâncias acadêmicas os proveitos da monitoria a fim de incorporá-la ao currículo formal e favorecer a participação dos graduandos.

Palavras-chave: mentores; Educação superior; capacitação de recursos humanos em saúde; ensino.

\begin{abstract}
Academic monitorship is a strategy that can help in professional health training by providing a dialogic channel between professors and students and favor teaching-learning processes. Thus, the objective of this study was to review the literature about monitorship and professional health training in Brazil and to identify its potentialities and difficulties. This is an integrative review with a systematic search of articles published until April 2017. It was carried out at the electronic libraries Scielo and Biblioteca Virtual em Saúde. Thirteen articles were found, most of them about monitorship in public universities in South and Southeast Brazil. Seven studies were about Nursing and Medicine courses only. Some identified potentialities were: decreased distances among the actors of monitorship, increasing of student learning and autonomy, and narrowing the monitor to teaching. Among the difficulties mentioned, there were: lack of time for joint work, and little participation of students in proposed activities. Most of the manuscripts were essentially descriptive, and did not emphasize the related theoretical and pedagogical aspects. Nevertheless, the set of articles suggests that monitorship can potentially add autonomy, criticality and humanization to student learning finetuned with social demands of health services. It is concluded that the theme academic monitorship is permeable for new studies and reflections about the teaching-learning processes focused on the specificities of the different health professions. It would be pertinent to discuss the educational benefits of monitorship in the various academic instances in order to incorporate it into the formal curriculum and then favor undergraduates' participation.
\end{abstract}

Keywords: mentors; education, higher; health human resource training; teaching.

Recebido em: 10/03/2018

Revisado em: $08 / 07 / 2018$

Aprovado em: 15/10/2018

Autor para correspondência: Ana Eliza Port Lourenço - Curso de Nutrição, Universidade Federal do Rio de Janeiro - Avenida Aluísio da Silva Gomes 50, Granja dos Cavaleiros - CEP: 27930-560 - Macaé (RJ), Brasil - E-mail: aelourenco@gmail.com

Conflito de interesse: Nada a declarar. 


\section{INTRODUÇÃO}

Ao analisar a trajetória do Sistema Único de Saúde (SUS) desde sua implantação, nota-se que houve avanços em diversos aspectos, incluindo, por exemplo, conquistas políticas, melhorias nos sistemas de informação e ampliação do acesso da população aos serviços de saúde ${ }^{1,2}$. Porém, são ainda inúmeros os desafios em termos de consolidação do sistema ${ }^{2}$, principalmente no cenário de desconstrução da democracia mediante a crise política iniciada em 2016, que compromete o direito à saúde ${ }^{2,3}$. Dentre os entraves de consolidação, têm-se problemas de gestão financeira, controle social diminuto e, especialmente, inadequação da formação dos profissionais de saúde para atuação no SUS ${ }^{3-5}$.

Tanto no cenário global quanto no brasileiro, alguns dos desafios para a formação profissional em saúde são: distanciamento dos profissionais em relação à realidade social e de saúde dos sujeitos; dificuldade dos profissionais acerca da construção do pensamento crítico; e aplicação frequente de métodos pedagógicos tradicionais, que reproduzem modelos assistenciais também conservadores ${ }^{5,6}$. Na busca por minimizar tais desafios é necessário redirecionar a formação profissional em saúde, que historicamente tem sido voltada para atender o mercado capitalista com foco no modelo biomédico em detrimento das demandas sociais ${ }^{5,7}$. Em movimento contra hegemônico, orientar a formação no sentido de fortalecer o SUS exige repensar as matrizes curriculares e as práticas pedagógicas nos cursos de graduação, a fim de articular o ensino superior com o serviço de saúde e a sociedade ${ }^{4,5}$.

A monitoria acadêmica está instituída no Brasil desde a década de 1960 e tem sua potencialidade pedagógica reconhecida na Lei de Diretrizes e Bases da Educação Nacional (LDB) ${ }^{8}$, sendo uma estratégia que pode contribuir com tal formação diferenciada. Conforme os monitores, tendo suporte do professor, auxiliam no aprendizado de colegas, a monitoria pode proporcionar um canal dialógico entre esses atores e vir a favorecer os processos de ensino-aprendizagem ${ }^{9}$.

Esses processos são diversos e a produção do conhecimento na monitoria, da mesma forma, pode ser encaminhada por diferentes percursos. Para Burke ${ }^{10}$ existem diferentes tipos de conhecimento, tais como: o científico, o social e o técnico-profissional. Vale destacar que a produção, recepção e reprodução do conhecimento envolvem as visões sociais no mundo dos alunos ${ }^{10}$, incluindo as crenças pessoais, as diferentes formas de coleta de informação, as posições ideológicas e epistêmicas, o grau de autonomia intelectual que é dado ao aluno, dentre outros aspectos. Dentro dessa concepção, são muitas variáveis em um jogo complexo de formação, e a monitoria pode contribuir nesse processo.

Cabe ressaltar que se espera que os profissionais de saúde exerçam a Educação em Saúde em sua rotina profissional, de forma dialogada e problematizadora como requer o modelo de assistência no SUS ${ }^{11}$. Sendo assim, durante a formação em saúde também se prevê o exercício de uma educação que entende a realidade de forma crítica e valoriza as vivências dos alunos, se contrapondo à maneira tradicional que coloca o aluno como mero receptor do conhecimento acadêmico formal ${ }^{12}$. Essa perspectiva educativa caminha afinada com a Política Nacional de Humanização, na ótica do desenvolvimento de práticas concretas comprometidas com a produção de saúde e produção dos sujeitos que levem à consideração do ser humano em sua capacidade criadora e singular ${ }^{13}$. Ao inserir o aluno na construção e desenvolvimento das disciplinas, a monitoria pode vir a auxiliar na aprendizagem em consonância com essa perspectiva educativa dialógica, contribuindo para a atuação profissional no SUS.

Todavia são escassos estudos que se debruçam na análise teórico-pedagógica da monitoria. Diferentemente da clareza sobre a relevância pedagógica da extensão universitária, que inclusive está sendo inserida na grade curricular dos cursos de graduação no país ${ }^{14}$, os benefícios da monitoria para a formação superior não se encontram consolidados.

No sentido de contribuir para essa consolidação, esse estudo tem por objetivo revisar a literatura sobre monitoria e formação profissional em saúde no Brasil, com vistas a identificar suas potencialidades e dificuldades.

\section{MÉTODOS}

Este estudo consiste em revisão integrativa da literatura que, de forma sistemática e ordenada, reúne e sintetiza resultados de múltiplas pesquisas sobre um fenômeno, para permitir conhecer o estado da arte e apontar caminhos para a realização de novos estudos ${ }^{15,16}$. Foi feita uma busca sistemática da literatura por duas pesquisadoras, de modo independente, nas principais bibliotecas eletrônicas na área da saúde, a saber: SciELO e Biblioteca Virtual em Saúde (BVS).

Foram utilizados descritores e palavras pré-selecionados. Optou-se pela busca aberta, incluindo todos os índices, em vez de busca estrita por descritores. Os termos utilizados em português foram combinados três a três, sendo um de cada grupo a seguir, até que se esgotassem as possibilidades de combinação: 1) "monitoria", "programa de monitoria", "monitorias" e "mentores"; 2) "educação superior", "ensino" e "ensino superior"; e 3) "Brasil". Também foram aplicados individualmente os termos "monitoria", "programa de monitoria" e "monitorias". Foi feita ainda busca com termos em inglês, combinados entre si: "mentors", "education high" e "Brazil".

A revisão ocorreu conforme as seis etapas propostas por Mendes et al. ${ }^{16}$ A primeira etapa consistiu na identificação do tema monitoria e seleção da questão norteadora da pesquisa, que foi "de que forma a monitoria acadêmica pode contribuir para a formação profissional em saúde?”.

$\mathrm{Na}$ segunda etapa foram estabelecidos critérios para inclusão e exclusão de estudos. Como critérios de inclusão, adotou-se: 1) ser 
estudo original que avalia experiências de monitoria em cursos de graduação na área da saúde em Instituição de Ensino Superior (IES) no Brasil; 2) apresentar relatos de casos e/ou de resultados de pesquisa, com abordagem quantitativa e/ou qualitativa; e 3) ser publicado antes de abril de 2017. Para fins de exclusão, por meio da leitura do título, foram suprimidos os artigos resultantes da busca que se repetiam. Daqueles restantes, foram lidos os resumos e, quando necessário, o corpo do texto para verificar se eram atendidos os critérios de inclusão. Posteriormente, os artigos adequados a esses critérios foram lidos na íntegra e analisados.

$\mathrm{Na}$ terceira etapa foram definidas as informações a serem extraídas dos trabalhos selecionados. Foi identificado o tipo de estudo e as ferramentas utilizadas. Nas pesquisas com sujeitos, foi avaliado se as entrevistas, questionários e/ou perguntas norteadoras utilizadas foram fechadas/objetivas ou abertas/dissertativas. Buscou-se identificar potencialidades e entraves mencionados nas experiências de monitoria. Mesmo que a potencialidade/entrave tenha sido citada somente em um dos estudos, essa foi incluída na sistematização.

A quarta etapa consistiu na avaliação dos estudos. Devido à particularidade do tema monitoria não ser vastamente explorado na literatura, optou-se apenas por verificar a indexação das revistas de publicação dos artigos segundo o critério qualis da Coordenação de Aperfeiçoamento de Pessoal de Nível Superior (CAPES), referente ao período de avaliação de 2013-2016. Foram considerados somente publicações em revistas avaliadas com, no mínimo, qualis "B" para as áreas "Ensino", "Educação" e "Saúde Coletiva". Buscou-se não estabelecer critérios que restringissem, mas sim que abarcassem o maior número de publicações.

A quinta etapa consistiu na interpretação dos resultados. As informações foram sumarizadas em quadros descritivos e foi verificada a articulação dos resultados com referenciais teóricos em pedagogia e formação superior em saúde. Na sexta e última etapa apresenta-se a síntese do conhecimento, abordada a seguir nesse estudo.

\section{RESULTADOS}

Na busca sistemática na SciELO e na BVS resultaram respectivamente 40 e 38 artigos sem repetição. Durante o processo de leitura para verificar se os estudos atendiam aos critérios de inclusão, não houve discordância entre as pesquisadoras, que identificaram um total de 13 artigos, sendo sete oriundos da SciELO e seis da BVS (Figura 1).

Dentre os 13 estudos encontrados, sete se referem exclusivamente à graduação em Enfermagem ou Medicina (Quadro 1). A maior parte dos estudos foi desenvolvida nas regiões Sul e Sudeste do Brasil, em instituições públicas. A data de publicação variou de 2003 a 2015. Destaca-se um estudo que realizou análise documental datada de 1985 a $2000^{17}$.
A metodologia dos estudos foi variada, incluindo o uso de questionários com perguntas objetivas ou combinação de parte objetiva com questões discursivas. Houve também estudos em que se aplicaram entrevistas semiestruturadas ou abertas. $\mathrm{Na}$ maior parte dos estudos, os respondentes eram monitores, embora em três tenham sido abordados professores orientadores e/ou alunos participantes da monitoria.

No que toca a revista de publicação, cabe destacar que todas se encontram atualmente indexadas pela CAPES com pelo menos avaliação "B" para as áreas de "Educação", "Ensino" e/ou "Saúde Coletiva".

Oito artigos apresentaram caráter predominantemente descritivo e restrito à interpretação dos dados quantitativos acerca da experiência de monitoria. Destes, apenas cinco apresentaram discussão teórica ${ }^{17-21}$.

Como pontos positivos da monitoria, foram mencionados nos estudos: ampliação do aprendizado, maior autonomia discente, aproximação do aluno monitor com a docência e estreitamento das relações aluno-professor no processo de aprendizagem. Como dificuldades para o desenvolvimento da monitoria, foram mencionados: escassez de tempo comum entre os estudantes para o trabalho em equipe e pouca participação desses alunos nas atividades propostas pelos monitores (Quadro 2).

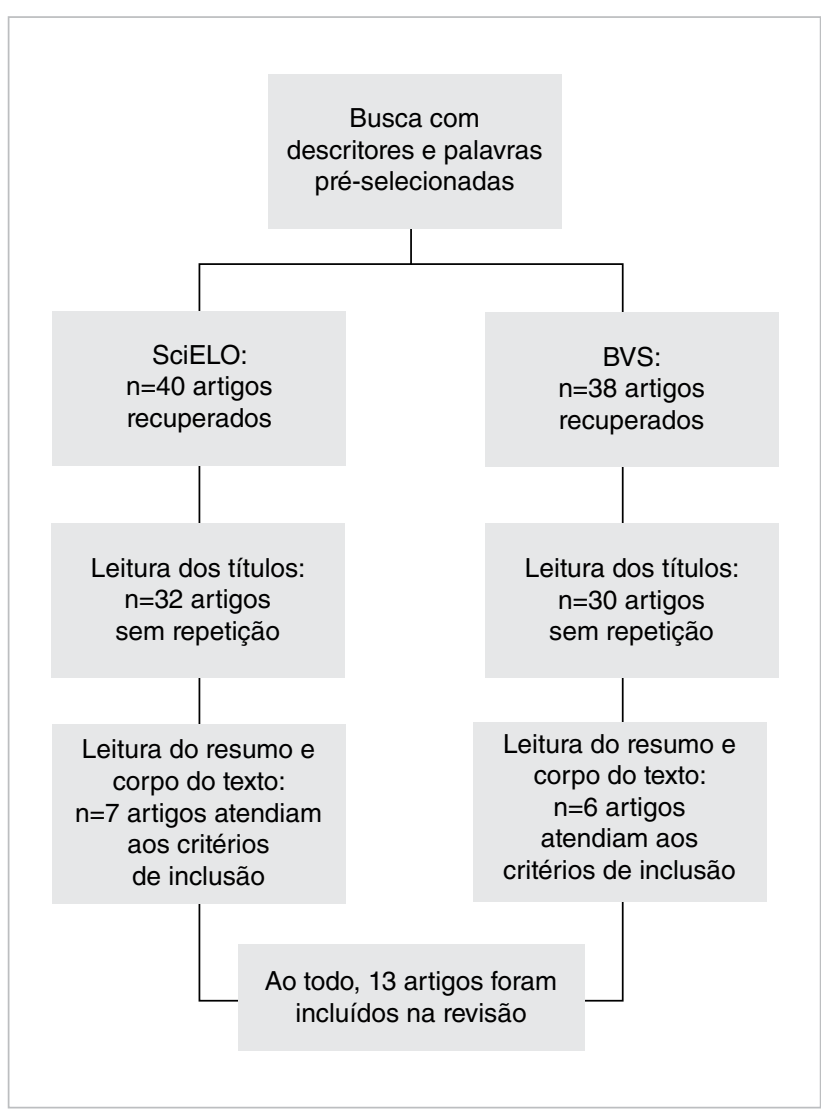

Figura 1: Fluxograma da seleção de artigos para a revisão integrativa 
Destaca-se que o estudo de Soares et al. ${ }^{22}$, Albuquerque et al. ${ }^{18}$, Santos e Batista ${ }^{19}$ trouxeram reflexões sobre os desafios e sugestões para a superação de problemas encontrados na monitoria, sendo que as inovações empregadas foram consideradas exitosas pelos autores.

\section{DISCUSSÃO}

A monitoria acadêmica é uma estratégia pedagógica de grande dimensão e abrangência no $\mathrm{Brasil}^{8}$. No entanto somente 13 estudos sobre o tema foram encontrados nesta revisão. Esse em si é um resultado importante, pois suscita questionar o porquê da monitoria não estar recebendo ênfase de produção acadêmica no domínio das principais bases de busca na área da saúde.

Cabe dizer que o pesquisador tende a estudar aquilo que lhe é conhecido e que lhe faz sentido dentro de seu paradigma de formação ${ }^{23}$. A formação pedagógica de docentes tem sido considerada um nó crítico em diferentes cursos de saúde, a exemplo do que dizem Costa ${ }^{24}$ e Damiance et al. ${ }^{25}$. Os professores, por vezes, possuem expertise em sua área específica, mas incipiente formação pedagógica, o que pode colaborar para o pouco interesse desses por investigar sobre monitoria.

Quadro 1: Características dos artigos encontrados na revisão

\begin{tabular}{|c|c|c|c|c|c|}
\hline Autores e Ano & $\begin{array}{l}\text { Instituição de } \\
\text { realização da } \\
\text { pesquisa }\end{array}$ & Curso & Características do Estudo & $\begin{array}{c}\text { Área principal da } \\
\text { Revista }\end{array}$ & $\begin{array}{l}\text { Qualis CAPES } \\
\text { Ensino; } \\
\text { Educação; } \\
\text { Saúde Coletiva }\end{array}$ \\
\hline Abreu et al. $2014^{23}$ & UERJ (RJ) & Enfermagem & $\begin{array}{l}\text { Entrevista semiestruturada } \\
\text { com } 11 \text { ex-monitores em } \\
2013\end{array}$ & Enfermagem & B1; B1; B3 \\
\hline $\begin{array}{l}\text { Albuquerque et al. } \\
2012^{10}\end{array}$ & Univasf (PE) - Pública & Medicina & $\begin{array}{c}\text { Relato de experiência } \\
\text { de quatro monitores de } \\
\text { medicina }\end{array}$ & Educação e Medicina & B1; B1; B2 \\
\hline $\begin{array}{l}\text { Albuquerque et al. } \\
2012^{28}\end{array}$ & UFBA (BA) & Medicina & $\begin{array}{c}\text { Questionário com perguntas } \\
\text { objetivas aplicadas a } 32 \\
\text { monitores em 2009-2010 }\end{array}$ & Educação e Medicina & B1; B1; B2 \\
\hline Assis et al. $2006^{27}$ & UERJ (RJ) & Cursos diversos & $\begin{array}{c}\text { Questionário com perguntas } \\
\text { objetivas aplicadas a } 126 \\
\text { alunos e } 101 \text { professores } \\
\text { em 2003-2004 }\end{array}$ & Enfermagem & B1; B1; B3 \\
\hline Borsatto et al. $2006^{9}$ & UERJ (RJ) & Enfermagem & $\begin{array}{l}\text { Análise documental de } 1985 \\
\text { a } 2000\end{array}$ & Enfermagem & A2; B1; B1 \\
\hline Carvalho et al. $2012^{24}$ & $\begin{array}{l}\text { Não especificada - } \\
\text { (RN) }\end{array}$ & Enfermagem & $\begin{array}{l}\text { Relato de experiência de } \\
\text { monitores em 2009-2010 }\end{array}$ & Enfermagem & B4; -; B4 \\
\hline Cechinel et al. $2005^{19}$ & UERJ (RJ) & $\begin{array}{l}\text { Biologia, Medicina, } \\
\text { Enfermagem } \\
\text { Odontologia e } \\
\text { Nutrição }\end{array}$ & $\begin{array}{l}\text { Questionário com perguntas } \\
\text { objetivas e discursivas } \\
\text { aplicadas a } 47 \text { monitores } \\
\text { em 2003-2004 }\end{array}$ & Enfermagem & B1; B1; B3 \\
\hline Dantas $2014^{12}$ & $\begin{array}{l}\text { UFRN (RN) e UnB } \\
\text { (DF) }\end{array}$ & Cursos diversos & $\begin{array}{c}\text { Análise documental e } \\
\text { entrevistas abertas com } \\
\text { professores e } 24 \text { monitores } \\
\text { em 2009-2013 }\end{array}$ & Educação & $\mathrm{A} 1 ; \mathrm{A} 2 ;-$ \\
\hline Haag et al. $2008^{25}$ & $\begin{array}{l}\text { UNISINOS (RS) - } \\
\text { Privada }\end{array}$ & Enfermagem & $\begin{array}{c}\text { Questionário com perguntas } \\
\text { objetivas aplicadas a } 25 \\
\text { alunos e } 4 \text { professores em } \\
2004-2005\end{array}$ & Enfermagem & B5; B1; B1 \\
\hline Mano e Carlos $2010^{21}$ & UFRGS (RS) & Psicologia & Ensaio teórico & Psicologia & B4; B1; B4 \\
\hline $\begin{array}{l}\text { Natario e Santos } \\
2010^{14}\end{array}$ & $\begin{array}{c}\text { Não especificada (SP) } \\
\text { - Privada }\end{array}$ & $\begin{array}{l}\text { Medicina, Farmácia e } \\
\text { Odontologia }\end{array}$ & $\begin{array}{l}\text { Questionário com perguntas } \\
\text { objetivas e discursivas } \\
\text { aplicado a } 19 \text { monitores }\end{array}$ & Psicologia & B1; A2; B3 \\
\hline $\begin{array}{l}\text { Santos e Batista } \\
2015^{11}\end{array}$ & UNIFESP (SP) & $\begin{array}{l}\text { Fisioterapia, Terapia } \\
\text { Ocupacional } \\
\text { Psicologia, Educação } \\
\text { Física e Nutrição }\end{array}$ & $\begin{array}{l}\text { Questionário com perguntas } \\
\text { discursivas aplicado a } 41 \\
\text { monitores }\end{array}$ & Saúde & B3; B5; B4 \\
\hline Soares et al. $2003^{15}$ & UFRJ (RJ) & Medicina & $\begin{array}{l}\text { Análise de mensagens } \\
\text { no ambiente virtual } \\
\text { de aprendizagem e } \\
\text { questionário com perguntas } \\
\text { objetivas aplicado a } 325 \\
\text { alunos em } 2000 \text { e } 2002\end{array}$ & Saúde & B3; B1; B1 \\
\hline
\end{tabular}

CAPES - Coordenação de Aperfeiçoamento de Pessoal de Nivel Superior; UERJ - Universidade do Estado do Rio de Janeiro; UNIVASF - Universidade do Vale do São Francisco; UFBA - Universidade Federal da Bahia; UFRN - Universidade Federal do Rio Grande do Norte; UnB - Universidade de Brasília; UNISINOS - Universidade do Vale do Rio dos Sinos; UFRGS - Universidade Federal do Rio Grande do Sul; UNIFESP - Universidade Federal de São Paulo; UFRJ - Universidade Federal do Rio de Janeiro. 
Os estudos encontrados privilegiaram instituições públicas e não representaram todas as regiões do país, o que impede que se conheça o tema diante da diversidade de condições de ensino no Brasil. O fato de somente seis dos artigos abordarem cursos de saúde para além de Enfermagem e Medicina ${ }^{19-21,26-28}$ denota outra carência na literatura.

Chama a atenção que os estudos não discutiram seus achados sobre monitoria à luz das especificidades de cada profissão. Ainda que as carreiras da área da saúde tenham aspectos em comum e devam se articular de modo interdisciplinar, cada uma tem sua identidade e atribuições. Tal diferença entre profissões requer estratégias específicas durante a graduação para a formação dos distintos profissionais.

A maioria dos artigos desta revisão não enfatiza aspectos teórico-pedagógicos, exceto os estudos em revistas nas áreas de educação e psicologia ${ }^{20,21,27}$. Essa situação denota o cunho essencialmente descritivo dos estudos e sugere que o tema monitoria na literatura encontra-se permeável para novas reflexões acadêmicas na interface entre saúde e educação.

Os estudos são unânimes em apontar os benefícios da experiência da monitoria. $\mathrm{O}$ exercício feito nesta revisão permitiu resgatar tais apontamentos e propor uma conexão entre esses benefícios e o aprimoramento da formação em saúde. Mesmo que os estudos não permitam adentrar nas especificidades de cada profissão, foi possível relacionar potencialidades da monitoria com aspectos das diretrizes curriculares que são comuns aos diversos cursos da saúde, tais como criticidade, autonomia e humanização $0^{4,5,29}$.

\section{Potencialidades da monitoria para a formação em saúde}

Nesta revisão evidencia-se que os monitores ampliam seu aprendizado à medida que estudam os conteúdos e se aprofundam na teoria ${ }^{18,19,26,27,30-32}$. Observa-se, ainda, que o crescimento intelectual dos monitores também decorre da aquisição de habilidades relacionadas à docência ${ }^{20,30-32}$. Por exemplo, Abreu et al. ${ }^{30}$ comentaram que, assim como seus professores, durante o aprendizado docente os monitores têm de exercitar a análise crítica ao selecionar informações de modo independente para trabalhar com os alunos.

Nesse sentido, tais aprendizados da monitoria podem favorecer a formação de profissionais de saúde mais críticos e reflexivos, o que é altamente requerido no SUS 5 . Além disso, ao desenvolverem maior criticidade e habilidades docentes, os monitores passam a protagonizar seu aprendizado, ampliando sua autonomia ${ }^{30}$. Pode-se vislumbrar que o exercício da autonomia durante a graduação contribua para a atuação profissional também autônoma, que é outra característica necessária no SUS, sobretudo ao profissional que atuará em equipes multidisciplinares ${ }^{29}$.

Destaca-se que aprender para ensinar torna-se uma necessidade dos monitores, diante das expectativas dos seus colegas e do comprometimento com os mesmos, de modo que tendem a ficarem mais atentos ao seu processo de aprendizado, identificando bloqueios e criando meios para superá-los, num processo de autorregulação $0^{9,30}$. Além disso, ao ajudar os colegas a estabelecer metas, organizar tarefas e melhorar estratégias de estudo, os monitores compartilham com eles modos de aprender a aprender.

Quadro 2: Potencialidades e dificuldades da monitoria acadêmica segundo os artigos encontrados na revisão

\begin{tabular}{|c|c|c|}
\hline \multicolumn{2}{|c|}{ Potencialidades e dificuldades da monitoria } & \multirow{2}{*}{$\begin{array}{c}\text { Referências } \\
\text { 18-19, 26-27, } \\
\text { 30-32 }\end{array}$} \\
\hline \multirow{9}{*}{ Potencialidades } & Ampliação da aprendizagem, reflexão e aprofundamento teórico dos monitores & \\
\hline & Melhoria das relações interpessoais dos monitores & $\begin{array}{l}\text { 19-20, 26-27, } \\
\quad 30-32\end{array}$ \\
\hline & Identificação e construção de vínculo entre alunos e monitores & 26, 30-32 \\
\hline & Maior identificação do monitor com seu curso & 30 \\
\hline & Desenvolvimento de habilidades docentes pelo monitor & $20,30-32$ \\
\hline & Monitores e alunos desenvolvem autonomia para conduzir seu próprio processo de aprendizagem & 30 \\
\hline & Monitoria amplia o interesse do monitor pela carreira acadêmica & $\begin{array}{l}19-20,26-27, \\
30\end{array}$ \\
\hline & Monitoria proporciona acolhimento, apoio emocional e motivação aos alunos & 27,32 \\
\hline & Desenvolvimento de estratégias pelo monitor para estimular criticidade e autonomia nos alunos & 30 \\
\hline \multirow{9}{*}{ Dificuldades } & Alunos procuram a monitoria somente no período anterior às provas & $22,30-31$ \\
\hline & Atividades consideradas importantes por monitores e orientadores não são executadas com frequência & 28 \\
\hline & Desinformação ou falta de clareza dos monitores e orientadores sobre papel da monitoria & $17,20,27$ \\
\hline & Dificuldade de conciliar horários entre os agentes da monitoria, principalmente em cursos integrais & $\begin{array}{l}17,22,26 \\
28,30\end{array}$ \\
\hline & Excesso de trabalho para os monitores e desorganização no decorrer das atividades & 30 \\
\hline & $\begin{array}{l}\text { Indisponibilidade de laboratórios e materiais para as atividades de monitoria e número elevado de } \\
\text { estudantes por turma }\end{array}$ & 26,31 \\
\hline & Integração monitoria-pesquisa é dificultada por falta de incentivo, recursos e tempo dos alunos & 18 \\
\hline & Pouca articulação da monitoria com a pesquisa e a extensão, gerando desestímulo nos monitores & 9,12 \\
\hline & Timidez, insegurança e inexperiência são obstáculos individuais para os monitores & 26,30 \\
\hline
\end{tabular}


Nesse sentido é possível criar uma relação, em que monitores aprendem melhor sobre como estudar, compartilham com seus colegas esse aprendizado, e esses também passam a construir um caminho próprio de aprendizado crítico e autônomo ${ }^{30}$.

Nesse movimento encadeado, é pertinente mencionar que os benefícios de aprendizado conferidos aos monitores podem se estender aos demais alunos também por meio do espelhamento desses no monitor. Tal espelhamento foi citado em alguns estu$\operatorname{dos}^{26,30,31,32}$, no sentido de que os estudantes se identificam com os monitores, tidos como modelo a ser seguido. Por exemplo, em pesquisa em IES na região Sul, Haag et al. ${ }^{32}$ ouviram dos alunos que os principais aspectos positivos da monitoria eram proporcionar "maior habilidade", "esclarecimento de dúvidas" e a "didática/atenção dos monitores". Tais alunos atribuíram esses aspectos à sua identificação com os monitores e à atenção diferenciada recebida desses, gerando acolhimento e um ambiente mais favorável ao diálogo e à construção compartilhada do conhecimento.

Esse potencial dialógico da monitoria pode favorecer a humanização durante a graduação e também na atuação profissional, pois compreende um conjunto de princípios e modos de relação dos sujeitos, num contexto de valorização da dimensão subjetiva, que incentiva o acolhimento e as trocas solidárias comprometidas com a promoção da saúde ${ }^{13}$. Nessa direção, os estudos aqui encontrados apontam que a monitoria consiste num espaço para tentativas e erros entre alunos, no qual há apoio emocional e acolhimento ${ }^{27,32,33}$.

Esta revisão salienta que a monitoria também estreita a relação entre monitores e orientadores ${ }^{26,30,31}$. Tal estreitamento decorre do convívio e colaboração contínuos para o melhoramento da disciplina. Por vezes, as reflexões educativas são extrapoladas para outras sobre a formação do monitor, podendo abranger também suporte pessoal. O monitor, como apontam Cechinel et al. ${ }^{26}$, recebe apoio emocional do orientador no âmbito de seu trabalho e isso se traduz em ganhos adicionais, como amadurecimento e superação de desafios no cotidiano universitário.

Entendendo a monitoria como um espaço de trocas de diversas naturezas e entre diversos estudantes, destaca-se que o professor também pode receber suporte didático de seu orientando. Abreu et al. ${ }^{30}$ comentaram que o monitor auxilia o professor a fornecer explicações coerentes com a realidade do alunato, por ter maior sensibilidade e compreensão acerca das barreiras ao aprendizado. Sendo assim, pode-se dizer que a monitoria tem potencial para aprimorar a prática do professor, uma vez que as percepções agregadas pelo monitor ao planejamento pedagógico estimulam o docente a expandir seu repertório didático.

Outro produto importante dessa aproximação com os orientadores é a valorização do magistério superior, que favorece a descoberta de possível vocação profissional pelos monitores ${ }^{19,20,26,27,30}$. Esse estreitamento de relações contribui para cumprir um dos objetivos centrais da monitoria: despertar interesse pela docência no aluno. Enquanto o monitor ajuda o orientador a renovar sua didática, também se espelha em seu trabalho, o que pode estimulá-lo a construir seu próprio perfil profissional enquanto educador.

Cabe ainda ressaltar que a monitoria expõe o monitor à lida com relações plurais e exige que flutue constantemente entre as posições de educador e educando. Esse é um exercício de empatia que auxilia no desenvolvimento de habilidades interpessoais e de liderança ${ }^{26,30}$. Tais aspectos são indispensáveis à atuação em saúde, na qual os profissionais lidam cotidianamente com o público, e precisam se articular de forma autônoma, mas interdependente, para solucionar problemas dinâmicos.

\section{Dificuldades à realização da monitoria}

Os estudos comentaram que as funções exercidas pelo monitor frequentemente se distanciam daquelas que podem de fato contribuir para a formação acadêmica ${ }^{27}$. Por vezes os monitores se limitam (ou são limitados) a auxiliar o professor em tarefas administrativas que, como mencionado por Natário e Santos ${ }^{27}$, não lhes apetecem e não se alinham com o devido papel da monitoria.

Segundo esta revisão, a divergência entre o que deveria ser realizado na monitoria e o que se tem oportunidade de fazer parece ter relação com a desinformação por parte dos agentes sobre o que de fato é a monitoria acadêmica ${ }^{17,20,27}$. Outro possível motivo é a escassez de tempo na grade curricular para os monitores conciliarem todas as atividades acadêmicas e ainda diversificarem o plano de trabalho na monitoria ${ }^{17,22,26,28,30}$.

Assis et al. ${ }^{28}$, em pesquisa com monitores em IES do Norte Fluminense, identificaram que $70,7 \%$ desses classificaram o acompanhamento das aulas práticas como importante; ao passo que $54,8 \%$ relataram jamais ter realizado tal atividade, denotando uma incongruência entre o que se espera da monitoria e o que tem sido possível realizar. Esses mesmos estudantes também perceberam que a falta de tempo relaciona-se com os interesses/prioridades dos orientadores e monitores.

Dentre os professores entrevistados no referido estudo, 91\% consideraram importante auxiliar o monitor na preparação de atividades; entretanto, somente $65 \%$ o fazem com frequência ao menos esporádica. Em concordância, no estudo de Abreu et al. ${ }^{30}$, monitores relataram que suas respectivas orientadoras estavam sempre ocupadas com outras demandas e não tinham tempo para ajudá-los.

A busca dos estudantes pela monitoria restrita aos períodos que antecedem as provas foi outro problema observado em artigos desta revisão ${ }^{22,30,31}$, que está associado com a dificuldade de agenda comum. Em vez de serem encontros dialógicos, as sessões de monitoria passam a ser focadas em dúvidas pontuais, visando melhorar o desempenho nas avaliações.

Pensando em superar tais limitações, Soares et al. ${ }^{22}$ relataram a experiência de uso de um ambiente virtual de aprendizagem para ensino de Epidemiologia, a fim de disponibilizar comunicação 
contínua, independente da presença física. Contudo, esses autores comentaram que o espaço virtual não conseguiu ampliar a aprendizagem crítica, pois, assim como os encontros presenciais, esse recurso foi utilizado apenas pontualmente pelos alunos, o que pode ser devido à ausência de hábito de estudo contínuo.

Abreu et al. ${ }^{30}$ também relataram que, diante da dificuldade de tempo para a monitoria, os professores orientam os monitores a cumprir parte de sua carga horária em atividades à distância no âmbito da pesquisa. Entendendo a monitoria como iniciação ao magistério, carreira que abarca atuação em ensino, pesquisa e extensão, é nítida a importância de desafiar o monitor a atuar nas três áreas de modo indissociável. Entretanto, ainda que as atividades de pesquisa feitas em caráter complementar possam ser indiretamente revertidas em benefícios ao ensino, o referido estudo denota não haver a integração desejada entre esses dois componentes do tripé universitário.

A respeito da importância dessa união de atividades, destaca-se o estudo de Borsatto et al. ${ }^{17}$ que, em análise sobre a implantação da monitoria na Universidade do Estado do Rio de Janeiro, identificaram existir, em 1993, uma discussão a respeito da migração de monitores para a iniciação científica, por perceberem o esgotamento de suas possibilidades de atuação. Acerca da importância da integração da monitoria com pesquisa e extensão, ressalta-se o estudo de Albuquerque et al. ${ }^{18}$, que traz uma experiência positiva na monitoria em Bioquímica. Segundo esses autores, a articulação com a pesquisa sedimenta o conhecimento teórico do estudante, que necessita solucionar problemas, tomar decisões, assumir responsabilidades e trabalhar em equipe. E a união com a extensão é relevante por aproximar a produção científica e a sociedade, dando resposta às suas demandas e contribuindo para o redirecionamento dos objetivos da IES.

Santos e Batista ${ }^{19}$, por sua vez, relataram que o Projeto Político e Pedagógico (PPP) de sua IES assume que a monitoria deve incluir a comunidade acadêmica. Isso amplia o escopo de atuação dos monitores, uma vez que passam a preparar e conduzir atividade extraclasse aberta a todos, nas quais se discutem assuntos de interesse comum, não exclusivos à disciplina da monitoria.

Em especial nos cursos de graduação que funcionam em período integral, Assis et al. ${ }^{28}$ apontam a existência de incongruência de tempo disponível entre a proposta da monitoria e a estrutura curricular. Nesse sentido, a inserção da monitoria no PPP dos cursos, de maneira inerente ao ensino e articulada com a pesquisa e a extensão, poderia ser um caminho para viabilizar o potencial pedagógico da monitoria.

\section{CONCLUSÃO}

Esta revisão revelou que há poucos estudos sobre a monitoria acadêmica e que a maioria desses apresenta cunho descritivo e não enfatiza os aspectos teórico-pedagógicos relacionados à monitoria e à formação de profissional em saúde. Logo, o campo da monitoria encontra-se aberto para novos estudos e reflexões acerca do processo de ensino e aprendizagem na formação em saúde no Brasil.

Os achados desta revisão apontam que a monitoria é uma estratégia educativa interessante à formação geral em saúde por ser um espaço de constituição de profissionais críticos, autônomos e que priorizam o cuidado com o outro.

Existe também espaço na monitoria para que os estudantes protagonizem a construção de seu conhecimento e compartilhem esses saberes entre si, o que pode favorecer futura autonomia profissional. A partir da experiência da autorregulação da aprendizagem vivenciada na monitoria, os alunos podem superar a percepção fragmentada dos processos de ensino e compreender a integralidade das etapas e funções de disciplinas e saberes necessários para o exercício da profissão.

A monitoria proporciona, ainda, aproximação entre orientador e monitor, o que pode despertar o interesse do aprendiz pela carreira docente. Por sua vez, monitores também ajudam os professores a contextualizarem sua prática à realidade dos estudantes, $\mathrm{o}$ que pode trazer aprimoramentos para a atuação docente.

Destacou-se nos estudos a falta de tempo comum entre os agentes da monitoria. Esse é um importante fator que limita a potencialidade da monitoria no ensino, bem como sua integração com a extensão e a pesquisa.

Esta revisão sugere a necessidade de ampliar nas diversas instâncias acadêmicas a discussão sobre os benefícios à formação conferidos pela monitoria. Assim seria possível incorporá-la ao currículo formal, de modo a favorecer a participação de um maior número de graduandos nas atividades.

Refletir sobre a monitoria e reconhecer seu potencial pedagógico para uma formação autônoma e crítica em saúde pode ser um caminho para preparar os egressos para a atuação nos serviços de saúde em consonância com os princípios do SUS.

\section{REFERÊNCIAS}

1. Vasconcelos CM, Pasche DF. O Sistema Único de Saúde. In: Campos GWS. Tratado de Saúde Coletiva. 2ed. São Paulo: Hucitec, 2012; p.531-62.

2. Paim JS. Sistema Único de Saúde (SUS) aos 30 anos. Ciênc Saúde Coletiva. 2018:23(6):1723-8

http://dx.doi.org/10.1590/S1414-32832001000200012
3. Campos GWS. SUS: o que e como fazer? Ciênc Saúde Coletiva. 2018:3(6):1707-14 http://dx.doi.org/10.1590/1413-81232018236.05582018

4. Batista CB. Movimentos de reorientação da formação em saúde e as iniciativas ministeriais para as universidades. Barbarói. 2013:(38):97-125. http://dx.doi.org/10.17058/barbaroi.v0i38.2567 
5. Costa MV, Borges FA. O pró-PET frente ao processo de formação profissional de saúde. Interface. 2015:19(Suppl.1):753-63. http://dx.doi.org/10.1590/1807-57622014.1057

6. Frenk J, Chen L, Bhutta ZA, Cohen J, Crisp N, Evans T, et al. Health professionals for a new century: transforming educations to strengthen health systems in na interdependent world. Lancet. 2010:376(9756):1923-58 http://dx.doi.org/10.1016/S0140-6736(10)61854-5

7. Santos LRCS, Sampaio RJ. Crise social das instituições de ensino superior e a formação em saúde para o mercado. Saude Debate. 2017:41(3):277-87

http://dx.doi.org/10.1590/S1414-32832001000200012

8. Brasil. República Federativa do Brasil. Lei n. 9.394, de 20 de dezembro de 1996. Estabelece as diretrizes e bases da educação nacional. Disponível em: http://www.planalto.gov.br/Ccivil 03/leis/ L9394.htm. Acesso em: 14 mar. 2018.

9. Frison LMB. Monitoria: uma modalidade de ensino que potencializa a aprendizagem colaborativa e autorregulada. ProPosições. 2016:27(1):133-53 http://dx.doi.org/10.1590/0103-7307201607908

10. Burke P. Uma história social do conhecimento. Rio de Janeiro: Zahar, 2003

11. Vasconcelos EM. Educação popular: instrumento de gestão participativa dos serviços de saúde. In: Brasil. Ministério da Saúde. Secretaria de Gestão Estratégica e Participativa. Caderno de Educação Popular e Saúde. Brasília: Ministério da Saúde, 2007; p. 18-29.

12. Freire P. Pedagogia do Oprimido. São Paulo: Paz e Terra; 2005

13. Brasil. Ministério da Saúde. Política Nacional de Humanização (PHN). Brasília: Ministério da Saúde. Disponível em: http://bvsms. saude.gov.br/bvs/publicacoes/politica nacional humanizacao pnh folheto.pdf. Acesso em: 14 mar. 2018.

14. Brasil. República Federativa do Brasil. Lei n. 13.005, de 25 de junho de 2014. Aprova o Plano Nacional de Educação - PNE e dá outras providências. Disponível em: http://www.planalto. gov.br/ccivil 03/ ato2011-2014/2014/lei/l13005.htm. Acesso em: 14 mar. 2018.

15. Vosgerau DS, Romanowski JP. Estudos de revisão: implicações conceituais e metodológicas. Rev Diálogo Educ. 2014:14(41):165-89.

http://dx.doi.org/10.7213/dialogo.educ.14.041.DS08

16. Mendes KDS, Silveira RCCP, Galvão CM. Revisão integrativa: método de pesquisa para a incorporação de evidências na saúde e na enfermagem. Texto Contexto Enferm. 2008:17(4):758-64 http://dx.doi.org/10.1590/S0104-07072008000400018

17. Borsatto AZ, Silva PDD, Assis F, Oliveira ENCC, Rocha PR, Lopes GT, et al. Processo de implantação e consolidação da monitoria acadêmica na UERJ e na Faculdade de Enfermagem (19852000). Esc Anna Nery. 2006;10(2):187-94 http://dx.doi.org/10.1590/S1414-81452006000200004

18. Albuquerque MAC, Amorim AHC, Rocha JRCF, Silveira LMFG, Neri DFM. Bioquímica como sinônimo de ensino, pesquisa e extensão: um relato de experiência. Rev Bras Educ Med. 2012;36(1):137-42. http://dx.doi.org/10.1590/S0100-55022012000100019
19. Santos GM, Batista SHSS. Monitoria acadêmica na formação em/ para saúde: desafios e possibilidades no âmbito de um currículo interprofissional em saúde. ABCS Health Sci. 2015;40(3):203-7. https://doi.org/10.7322/abcshs.v40i3.796

20. Dantas OM. Monitoria: fonte de saberes à docência superior. Rev Bras Estud Pedagog. 2014;95(241):567- 89 http://dx.doi.org/10.1590/S2176-6681/301611386

21. Mano GCM, Carlos SA. Prática de monitoria e construção de território. Psico. 2010; 41(4):473-8.

22. Soares ALAG, Dias CP, Vidal EIO, Coeli CM, Almeida LM, Camargo Júnior KR. Utilização de um serviço de monitoria virtual voltado para o ensino de epidemiologia na graduação médica. Physis. 2003; 13(1):39-58

http://dx.doi.org/10.1590/S0103-73312003000100003

23. Fourez GA. Construção das Ciências: introdução à filosofia e à ética das ciências. São Paulo: UNESP, 1995.

24. Costa NMSC. Formação pedagógica de professores de nutrição: uma omissão consentida? Rev Nutr. 2009;22(1):97-104. http://dx.doi.org/10.1590/S1415-52732009000100009

25. Damiance PRM, Tonete VLP, Daibem AML, Ferreira MLSM, Bastos JRM. Formação para o SUS: uma análise sobre as concepções e práticas pedagógicas em saúde coletiva. Trab Educ Saúde. 2016;14(3):699-721.

http://dx.doi.org/10.1590/1981-7746-sol00014

26. Cechinel MP, Lopes GT, Oliveira ACH, Camacho KG. As relações sociais entre os diferentes sujeitos da monitoria acadêmica em um centro biomédico. Rev Enferm UERJ. 2005;13:51-56.

27. Natário EG, Santos AAA. Programa de monitores para o ensino superior. Estud Psicol. 2010; 27(3):355-64. http://dx.doi.org/10.1590/S0103-166X2010000300007

28. Assis F, Borsatto AZ, Silva PDD, Peres PL, Rocha PR, Lopes GT Programa de Monitoria Acadêmica: percepções de monitores e orientadores. Rev Enferm UERJ. 2006;14(3):391-7.

29. Almeida MCP, Mishima SM. O desafio do trabalho em equipe na atenção à Saúde da Família: construindo "novas autonomias" no trabalho. Interface Comun Saúde Educ. 2001;5(9):150-3. http://dx.doi.org/10.1590/S1414-32832001000200012

30. Abreu TO, Spindola T, Pimentel MRAR, Xavier ML, Clos AC, Barros AS. A monitoria acadêmica na percepção dos graduandos de enfermagem. Rev Enferm UERJ. 2014;22(5):507-12. http://dx.doi.org/10.1590/S1414-32832001000200012

31. Carvalho IS, Lima Neto AV, Freitas Segundo FCF, Carvalho GRP, Nunes VMA. Monitoria em semiologia e semiotécnica para a enfermagem: um relato de experiência. Rev Enferm UFSM. 2012;2(2):464-71. http://dx.doi.org/10.5902/217976923212

32. Haag GS, Kolling V, Silva E, Melo SCB, Pinheiro M. Contribuições da monitoria no processo ensino-aprendizagem em enfermagem. Rev Bras Enferm. 2008;61(2):215-2. http://dx.doi.org/10.1590/S0034-71672008000200011

33. Albuquerque GS, Mendes RRS, Rocha BC, Carreiro MC. Monitoria de técnica operatória e cirurgia experimental e sua relevância na formação médica. Rev Bras Educ Méd. 2012;36(4):564-9. http://dx.doi.org/10.1590/S0100-55022012000600017 